\title{
First Record of an Annulated Seasnake, Hydrophis cyanocinctus (Daudin 1803), from the Surat District, South Gujarat, India
}

\author{
Dikansh S. Parmar
}

Department of Biosciences, Veer Narmad South Gujarat University, Surat, Gujarat, India (Ophiophagus_hannah10@yahoo.com)

$\mathrm{T}^{\mathrm{s}}$ he Annulated Seasnake (Hydrophis cyanocinctus) is a venomous viviparous snake that occurs along the entire coast of India (Fig. 1) within a broader distribution along coastal regions from the Persian Gulf to Japan and the IndoAustralian Archipelago (Whitaker and Captain 2008; RezaieAtagholipour et al. 2016). Hydrophis cyanocinctus generally inhabits shallow coastal waters, where it is often accidentally caught by prawn trawlers (Das 2006). Unlike many sea snakes, $H$. cyanocinctus can crawl slowly on land (Whitaker and Captain 2008).

During a field survey at $1322 \mathrm{~h}$ on 22 December 2018, we found a dead but intact Annulated Seasnake (Fig. 2)

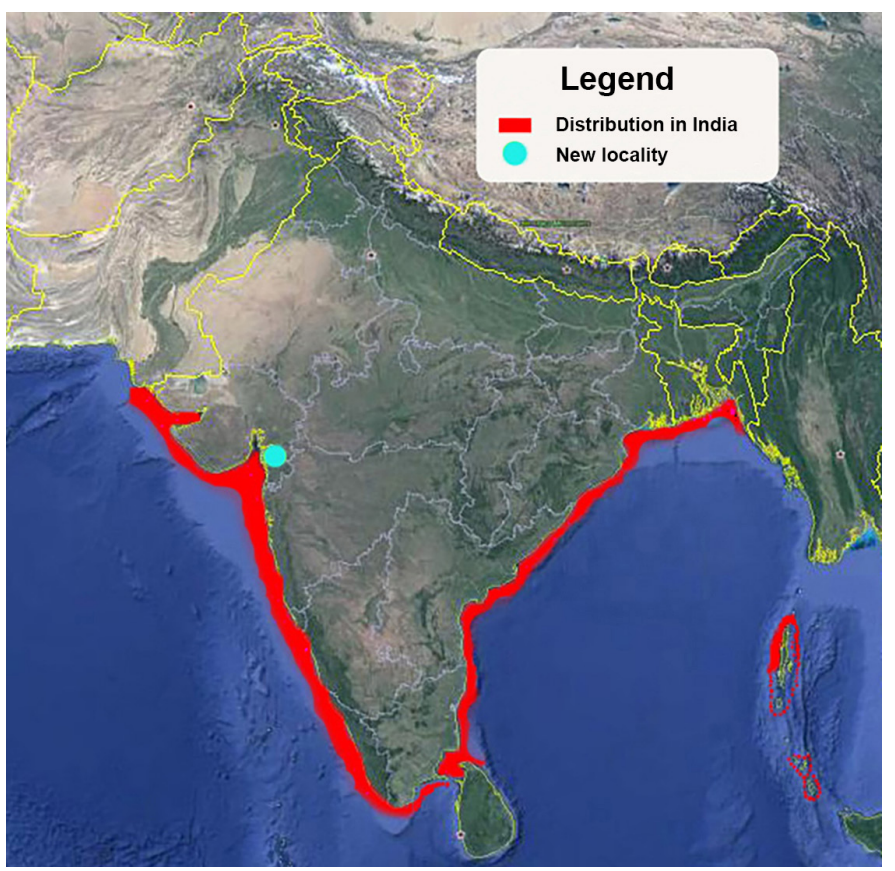

Fig 1. Distribution of the Annulated Sea Snake (Hydrophis cyanocinctus) in India showing the new locality in Dumas, Surat District, Gujarat. washed ashore at Sulatanabad on Dumas Beach of the Surat District, South Gujarat, India ( $\left.21^{\circ} 04^{\prime} 45^{\prime \prime N} 72^{\circ} 42^{\prime} 55^{\prime \prime E}\right)$. This is the first record of this species from South Gujarat and only the second record from Gujarat State; the first record was from the Jamnagar District in the Saurashtra Region of Gujarat (Chandrasekar et al. 2018), which is in northwestern Gujarat $>500 \mathrm{~km}$ from the Surat District.

The adult female measured 1,264.5 $\mathrm{mm}$ SVL and tail length $118.1 \mathrm{~mm}$. Dorsal scales were in 30:41:39 rows behind the head, at midbody, and anterior to the vent, respectively. Ventrals numbered 353 and subcaudals 53.

Daniel (2002) stated that no information on the diet of this species existed. However, snakes kept at the Madras (now Chennai) Aquarium are fed chopped fish. Whitaker and Captain (2008) indicated that these snakes feed on fish and eels. According to a more recent study in the Iranian Hara (Mangrove) Protected Area (Rezaie-Atagholipour et al. 2013), 27 of 35 prey items consumed by 19 of 34 snakes containing intact or partially digested prey included four species of gobiid fish, with all but one fish a mudskipper (subfamily Oxudercinae). The snake that we found had two freshly consumed mudskippers in its stomach.

Whitaker and Captain (2008) stated that this species is uncommon in Indian coastal regions; however, Desai (2017) listed it as a widely distributed common species along the coastline in Gujarat. Although I have seen 40-50 seasnakes caught in nets or trawls, all were Common Seasnakes (Hydrophis schistosus) and none were H. cyanocinctus.

This species is listed as being of Least Concern on the IUCN Red List (Rasmussen et al. 2010) despite the threat posed by trawl fisheries. However, marine life along the Surat coast also is seriously threatened by pollution generated by major coastal industries and toxic wastes released into estuaries (e.g., Parmar 2018), suggesting that the long-term sustainability of seasnake populations in this region is anything but assured. 


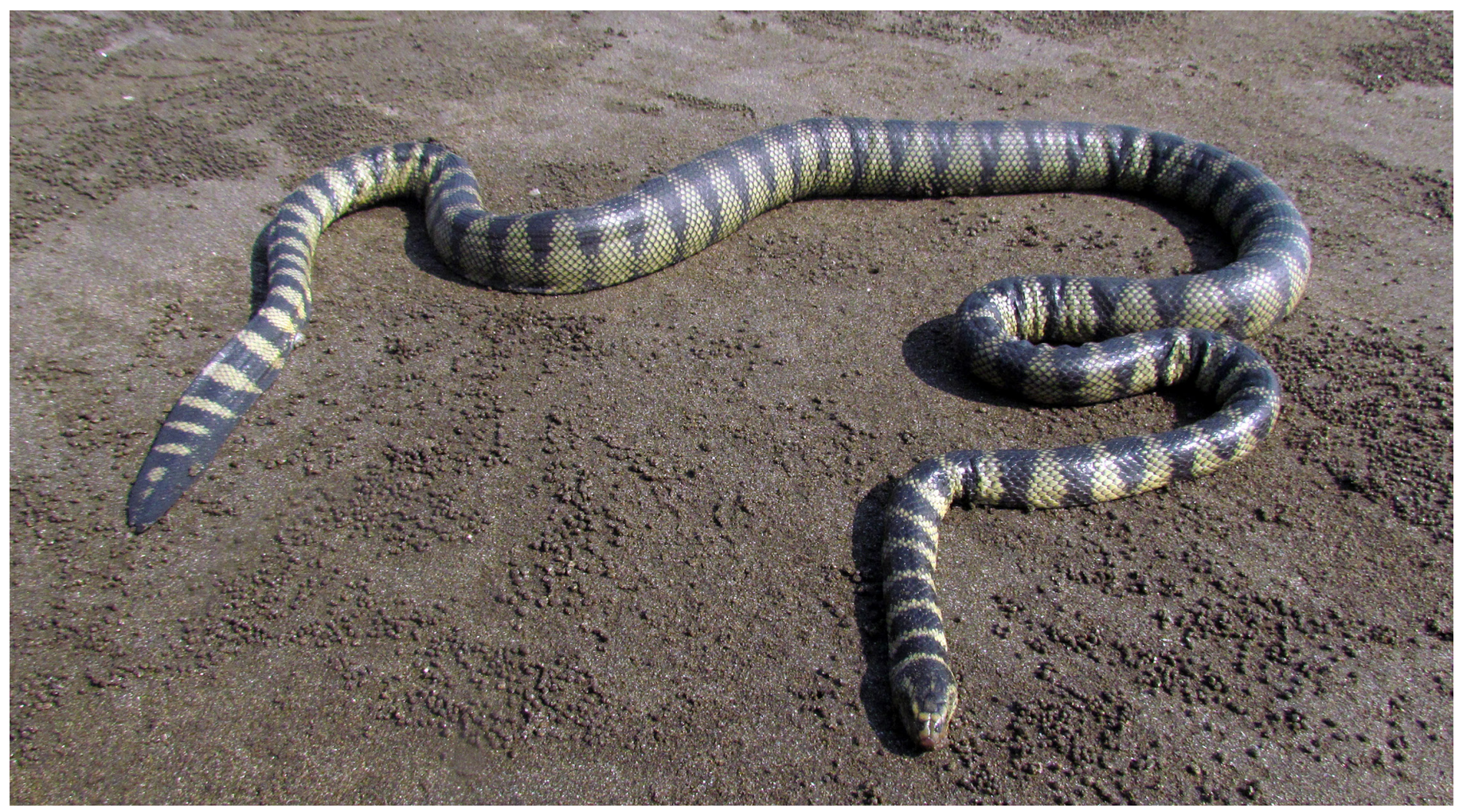

Fig 2. A dead but intact Annulated Seasnake (Hydrophis cyanocinctus) washed ashore at Sulatanabad on Dumas Beach of the Surat District, South Gujarat, India. Photograph by the author.

\section{Acknowledgements}

I thank Mahamad Jahid A. Patel, Moksh H. Patel, Hardik V. Prajapati, and Piyush Kumar P for logistic support and help during field surveys. A special thanks to Divyesh G. Gamit for helping in specimen preservation. I also thank Dr. Shantilal K. Tank, H.O.D. of the Department of Biosciences for his support and interest in our findings. I thank Vrajesh D. Patel for helping with the map.

\section{Literature Cited}

Chandrasekar, K., S. Balakrishnan, G. Arun, C. Satyanarayana, and K. Venkataraman. 2018. New observation of intertwined Annulated Sea Snake Hydrophis cyanocinctus (Reptilia: Elaphidae: Hydrophiinae) from Pirotan Island, Gulf of Kutch. Indian Journal of Geo-Marine Sciences 47: 2465-2468.

Daniel, J.C. 2002. The Book of Indian Reptiles and Amphibians. Bombay Natural History Society, Bombay, India.
Das, I. 2006. A Photographic Guide to Snakes and Other Reptiles of Borneo. Ralph Curtis Publishing, Sanibel Island, Florida.

Desai, A. 2017. Sarp Sandarbh. Gujarat na saap vishay ni Mahiti [= Regarding Snakes. Information about Snakes of Gujarat]. 6th ed. Prakruti Mitra Mandal, Dahod, Gujarat (in Gujarati).

Parmar, D. 2018. First record of a Yellow-bellied Sea Snake, Hydrophis platurus (Linnaeus 1766), from Gujarat, India. Reptiles \& Amphibians 25: 137-138.

Rasmussen, A., K. Sanders, and A. Lobo. 2010. Hydrophis cyanocinctus. The IUCN Red List of Threatened Species 2010: e.T176726A7291386.

Rezaie-Atagholipour, M., A. Riyahi-Bakhtiari, and M. Sajjadi. 2013. Feeding habits of the Annulated Sea Snake, Hydrophis cyanocinctus, in the Persian Gulf. Journal of Herpetology 47: 328-330.

Rezaie-Atagholipour, M., P. Ghezellou, M.A. Hesni, S.M.H Dakhteh, H. Ahmadian, and N. Vidal. 2016. Sea snakes (Elapidae, Hydrophiinae) in their westernmost extent: An updated and illustrated checklist and key to the species in the Persian Gulf and Gulf of Oman. ZooKeys 622: 129-164.

Whitaker, R. and A. Captain. 2008. Snakes of India, The Field Guide. First reprint edition. Draco Books, Chennai, India. 